\title{
Mystery Case: Parietal lobe epilepsy with ictal manifestation of Gerstmann syndrome
}

Hui Ming Khoo, MD, PhD, Yuya Fujita, MD, Naoki Tani, MD, PhD, Satoru Oshino, MD, PhD, Kuriko Kagitani-Shimono, MD, PhD, and Haruhiko Kishima, MD, PhD

Neurology ${ }^{\circledR}$ 2020;94:e430-e433. doi:10.1212/WNL.0000000000008841

\section{Pearls}

- Gerstmann syndrome, comprising finger agnosia, right-left disorientation, dysgraphia, and dyscalculia, is an uncommon manifestation of epileptic seizures. These signs can be easily overlooked unless tested specifically.

- A careful clinical testing of ictal symptoms can contribute to revealing unnoticed negative symptoms, and eventually the diagnosis and localization of epileptic foci.

\section{Oy-sters}

- Manifestation of negative symptoms such as Gerstmann syndrome during a seizure can present diagnostic pitfalls.

- Although positive symptoms such as automatisms, hand dystonia, myoclonic jerking, or tonic-clonic movements are common and well-known ictal signs, negative symptoms should not preclude epileptic seizures. For instance, a loss of ability to write or right-left confusion may be signs of a seizure, instead of a vascular event such as a TIA or stroke.

A 65-year-old right-handed woman of normal development started to experience episodes of right hand apraxia that could last for minutes to hours. She was aware during these episodes and was able to recall the episodes later. Episodes of apraxia that she described include sudden transient inability to turn the steaks that she was cooking on a pan and had to turn off the fire instead, inability to use and to release a knife that she was holding in her right hand and had to use her left hand to help release her right fingers off the knife, and inability to hang clothes on a clothesline. She consulted our epilepsy center when she was 71 years old for the increased frequency of her episodes to a weekly basis, despite treatment with multiple antiepileptic medications (carbamazepine $800 \mathrm{mg} /$ day, lamotrigine $200 \mathrm{mg} / \mathrm{day}$, and zonisamide $400 \mathrm{mg} /$ day). Continuous video-EEG monitoring revealed occasional slowing over the left centro-parietal region without a definite interictal epileptic discharge. During interictal periods, she scored full on the Mini-Mental State Examination, indicative of normal cognitive function, and her neurologic examination was normal. The examination included asking her to say her own name, orientation of place and time, to raise both arms or legs, to move fingers randomly (mimicking piano playing), to distinguish difference in soft touch on each side of her body (for detecting possible sensory deficit), to name objects, to repeat words or short sentences, to write a sentence, to calculate, to imitate meaningless hand gestures, to use tools available at the bedside (such as chopsticks, spoon, pen), to indicate her own body parts under verbal commands (such as right or left index finger, thumbs, toe, leg, nose, mouth), and to recall or recognize objects presented previously. The same examination during an ictal event revealed right hand kinetic apraxia, bilateral ideomotor apraxia, buccofacial apraxia, and Gerstmann syndrome (finger agnosia, right-left disorientation, dysgraphia, and dyscalculia) accompanied by neither aphasia nor impaired awareness. During the event, EEG demonstrated intermixed lateralized rhythmic delta/theta activity over the left fronto-centro-parietal region (figure, A) that waxed and waned for 6 hours and 19 minutes, indicative of a nonconvulsive status

\section{Correspondence}

Dr. Khoo

khoo@

nsurg.med.osaka-u.ac.jp

MORE ONLINE

Survey and results

NPub.org/mc9404

From the Epilepsy Center (H.M.K., N.T., S.O., K.K.-S., H.K.), Osaka University Hospital; Departments of Neurosurgery (H.M.K., Y.F., N.T., S.O., H.K.) and Pediatrics (K.K.-S.), Osaka University Graduate School of Medicine; and Division of Developmental Neuroscience (K.K.-S.), United Graduate School of Child Development, Osaka University, Suita, Japan.

Go to Neurology.org/N for full disclosures. Funding information and disclosures deemed relevant by the authors, if any, are provided at the end of the article. 

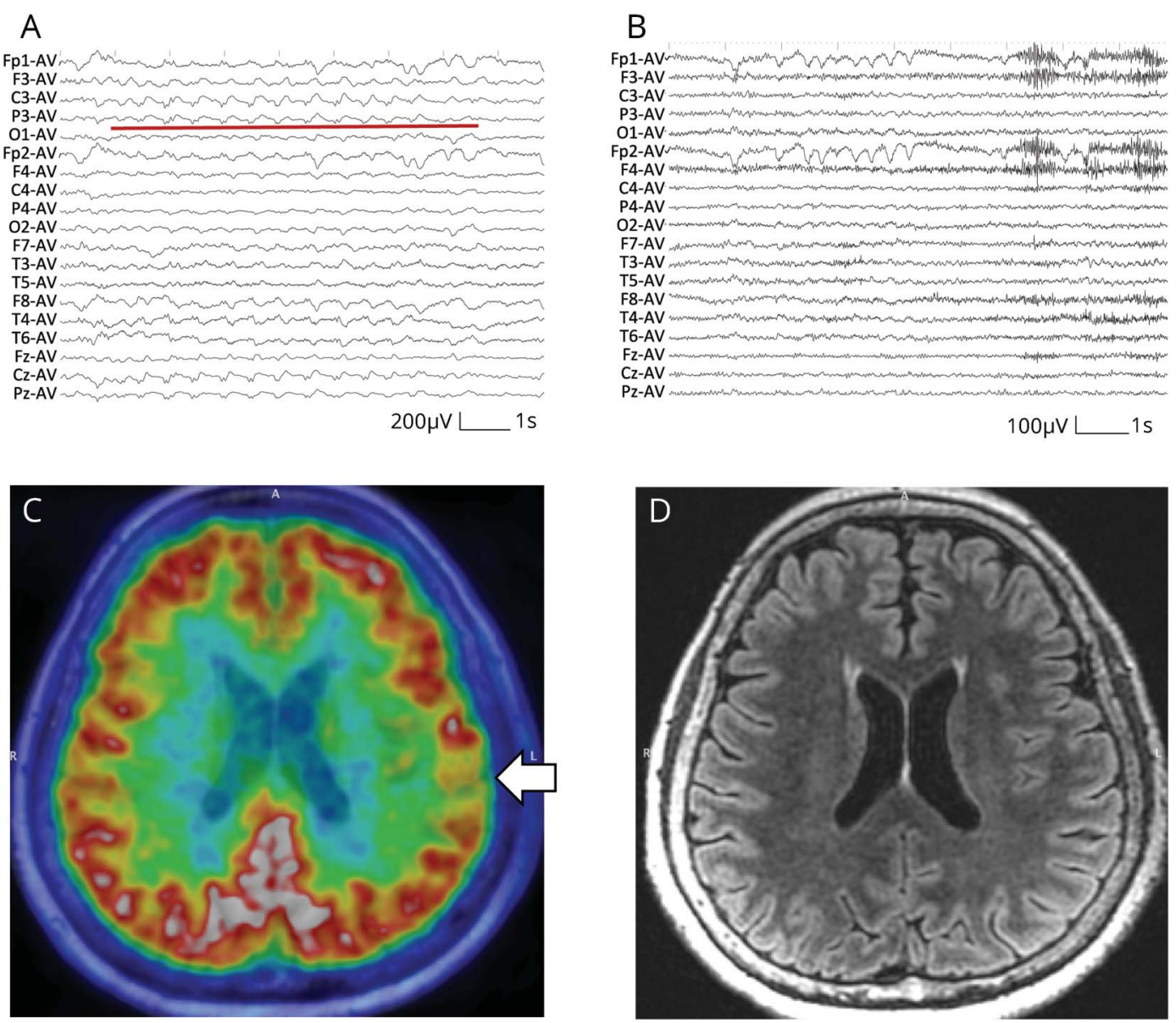

EEG during one of the nonconvulsive status epilepticus episodes shows an intermixed lateralized rhythmic delta/theta activity over the left fronto-centroparietal region (A) and following an IV injection of $5 \mathrm{mg}$ diazepam (B) in average montage. (C) Interictal FDG-PET (overlaid on coregistered MRI) revealed hypometabolism in the left supramarginal and angular gyrus. (D) MRI reveals no apparent structural abnormality (only the T2-weighted fluid-attenuated inversion recovery is shown here).

epilepticus. These deficits ameliorated with a quick return of the EEG to baseline (figure, B) following an IV injection of $5 \mathrm{mg}$ diazepam, confirming their epileptic nature. Imaging studies revealed hypometabolism in the left supramarginal and angular gyrus on interictal FDG-PET (figure, C) without a definite structural abnormality on MRI (figure, D). Based on the ictal symptoms and the FDG-PET findings, we concluded that the epileptic focus is located within the eloquent cortex and the patient is not a good candidate for surgical resection. Since responsive neurostimulator is yet to be approved in our country, the best option is to offer further optimization of antiepileptic medications or implantation of a vagal nerve stimulator.

\section{Discussion}

Gerstmann syndrome comprises a tetrad of finger agnosia, right-left disorientation, dysgraphia, and dyscalculia. ${ }^{1} \mathrm{Al}-$ though this syndrome is well-documented in patients with dominant parietal lesion and as a possible consequence of surgical resection in patients with parietal lobe epilepsy, ${ }^{1-3}$ combinations of either all or partially the symptoms are uncommon ictal manifestation; only 3 cases with seizure associated with transient Gerstmann syndrome have been reported despite numerous case series of parietal lobe epilepsy being reported to date. ${ }^{2,4-6}$ Hojo and Fukushima ${ }^{4}$ reported on a case of a 21-year-old patient with focal status epilepticus demonstrating Gerstmann syndrome in addition to aphasia, ideomotor apraxia, and color agnosia. Shimotake et al. ${ }^{5}$ reported on a case of a 34-year-old patient presenting with ictal events comprising 3 of the tetrad (absence of right-left disorientation) 12 years after resection of a left parietal astrocytoma. Zollner et al. ${ }^{6}$ reported on a case of a 44-year-old patient who had a large postsurgical defect in the temporooccipital region who presented with focal status epilepticus demonstrating acalculia and left-right disorientation in addition to anomia and alexia following a visual aura. Apart from its rarity, underdetection of these symptoms during a seizure may also explain the rarity of this syndrome being an ictal manifestation. Because seizures predominantly manifest positive symptoms such as automatisms, hand dystonia, myoclonic jerking, and tonic-clonic movements, ${ }^{7}$ these negative 
symptoms can be easily overlooked in most cases unless clinicians are looking for them or patients report them spontaneously. In our case, apart from confirming the symptom that the patient reported (apraxia), clinical testing has contributed to revealing negative symptoms that were not spontaneously reported (Gerstmann syndrome). These highlight the importance of clinical testing and of including some simple neuropsychological tests whenever possible while documenting ictal events during continuous video-EEG monitoring. Simple tests such as naming, calculation, imitating meaningless hand gestures, and indicating the patient's own body parts under verbal commands would be practical to be added to the standard tests performed at the epilepsy monitoring unit to help in seizure lateralization or localization, if the patient was cooperative and if the seizure duration was long enough for testing.

Gerstmann syndrome was observed during status epilepticus in all the cases reported to date. ${ }^{4-6}$ Interestingly, Shimotake et al. ${ }^{5}$ did not find Gerstmann signs during the presence of ictal discharges (sustained repetitive spikes) in their patient, although those signs emerged intermittently and frequently until a reduction in the frequency of the ictal discharges was confirmed in a 30-minute EEG recorded later. In our patient, Gerstmann syndrome and other negative symptoms occurred during the sustained waxing and waning of the epileptic activity. These observations suggest that a phenomenon similar to Todd paresis may have developed during short transient wane phases of the ictal activity, which may be associated with the negative nature of those signs. However, clarification of the exact relationship between the occurrence of the signs and the changes in the ictal activity can be challenging because the wane phases may be too short for testing the patient.

We did not offer surgical resection to our patient because of the possibility of a permanent Gerstmann syndrome from the resection. ${ }^{2}$ Gerstmann syndrome, despite later criticisms and debate over decades since its first mention in $1924{ }^{8}$ maintained its clinical localization value, that is, its association with the dominant parietal lobe. ${ }^{3}$ Although being less appreciated in the era of neuroimaging, its localization value is still important in the field of epilepsy because a large proportion of cases of focal epilepsy are nonlesional; clinical features remain to be the main contributor to the localization of epileptic foci in these patients. In this context, the same value applies to other signs; hand dystonias and automatisms (associated with temporal lobe contralateral to the dystonic hand and ipsilateral to the hand showing automatisms), intelligible speech (associated with nondominant temporal lobe), ${ }^{9}$ ictal pouting, and hypermotor behaviors (associated with frontal lobe) ${ }^{10}$ are a few examples of the well-known ictal lateralizing or localizing signs. A good electroclinical correlation and their concordance with other neuroimaging findings may further enhance the diagnostic confidence of these signs for localizing the epileptogenic zone, especially in patients without an MRI lesion, as demonstrated in this case report.

\section{Study funding}

No targeted funding reported.

\section{Disclosure}

H.M. Khoo is funded by a Grant-in-Aid for Scientific Research (18H06261, 19K21353) from the Ministry of Education, Culture, Sports, Science and Technology of Japan. She was supported by the Mark Rayport and Shirley Ferguson Rayport fellowship in epilepsy surgery from the Montreal Neurologic Institute (Canada), a research fellowship of the Uehara Memorial Foundation (Japan). She received a sponsored award from the Japanese Epilepsy Society, support from the American Epilepsy Society (AES) Fellows program, and travel bursary from the International League Against Epilepsy (ILAE). Y. Fujita is funded by Grant-in-Aid for Scientific Research (19K18388) from the Ministry of Education, Culture, Sports, Science and Technology of Japan. N. Tani is funded by Grant-in-Aid for Scientific Research (17K10895) from the Ministry of Education, Culture, Sports, Science and Technology of Japan and received research support from Mitsui-Kousei Foundation, funding for a trip from Medtronic, royalties from the publication of articles (Gakken Medical Shujunsha, Igaku-shoin), and honoraria from serving as speaker (Medtronic, Daiichi-Sankyo Pharmaceuticals, Eisai Pharmaceuticals). S. Oshino is funded by a Grant-in-Aid for Scientific Research (17K10894) from the Ministry of Education, Culture, Sports, Science and Technology of Japan. He received royalties from the publication of articles (Medicalview, Igaku-shoin) and honoraria from serving as speaker (Insightec, Eisai Pharmaceuticals, Daiichi-Sankyo Pharmaceuticals, UCB, Otsuka Pharmaceuticals, Teijin Pharma, Yamasa Corporation). K. Kagitani-Shimono is funded by a Grant-in-Aid for Scientific Research (18K07843) from the Ministry of Education, Culture, Sports, Science and Technology of Japan, receives institutional support from the Osaka University Graduate School, and research support from Eisai Pharmaceuticals. She serves on the speaker's bureau of Novartis Pharmaceuticals, Otsuka Pharmaceuticals, UCB, Alfresa Pharmaceuticals, and Daiichi-Sankyo Pharmaceuticals and received royalties from publication in Shindan-to-Chiryo-sha. H. Kishima is funded by a Grant-in-Aid for Scientific Research (18H04085, 18H05522, 16K10212, 16K10786) from the Ministry of Education, Culture, Sports, Science and Technology of Japan, Cross-ministerial Strategic Innovation Promotion Program (SIPAIH18E01), Japan Agency for Medical Research and Development, and Japan Epilepsy Research Foundation. Go to Neurology.org/N for full disclosures.

\begin{tabular}{|c|c|c|c|}
\hline Name & Location & Role & Contribution \\
\hline $\begin{array}{l}\text { Hui Ming } \\
\text { Khoo, MD, } \\
\text { PhD }\end{array}$ & $\begin{array}{l}\text { Epilepsy Center, Osaka } \\
\text { University Hospital; } \\
\text { Department of } \\
\text { Neurosurgery, Osaka } \\
\text { University Graduate } \\
\text { School of Medicine, } \\
\text { Suita, Japan }\end{array}$ & Author & $\begin{array}{l}\text { Designed and } \\
\text { conceptualized study, } \\
\text { major role in the care } \\
\text { of the patient, } \\
\text { deciding the } \\
\text { treatment option for } \\
\text { the patient, drafted } \\
\text { the manuscript for } \\
\text { intellectual content }\end{array}$ \\
\hline
\end{tabular}


Appendix (continued)

\begin{tabular}{|c|c|c|c|}
\hline Name & Location & Role & Contribution \\
\hline $\begin{array}{l}\text { Yuya } \\
\text { Fujita, MD }\end{array}$ & $\begin{array}{l}\text { Epilepsy Center, Osaka } \\
\text { University Hospital; } \\
\text { Department of } \\
\text { Neurosurgery, Osaka } \\
\text { University Graduate } \\
\text { School of Medicine }\end{array}$ & Author & $\begin{array}{l}\text { Major role in the care } \\
\text { of the patient, } \\
\text { deciding the } \\
\text { treatment option } \\
\text { for the patient, } \\
\text { revised the } \\
\text { manuscript } \\
\text { for intellectual } \\
\text { content }\end{array}$ \\
\hline $\begin{array}{l}\text { Naoki } \\
\text { Tani, MD, } \\
\text { PhD }\end{array}$ & $\begin{array}{l}\text { Epilepsy Center, Osaka } \\
\text { University Hospital; } \\
\text { Department of } \\
\text { Neurosurgery, Osaka } \\
\text { University Graduate } \\
\text { School of Medicine }\end{array}$ & Author & $\begin{array}{l}\text { Decided the } \\
\text { treatment option } \\
\text { for the patient, } \\
\text { revised the } \\
\text { manuscript } \\
\text { for intellectual } \\
\text { content }\end{array}$ \\
\hline $\begin{array}{l}\text { Satoru } \\
\text { Oshino, } \\
\text { MD, PhD }\end{array}$ & $\begin{array}{l}\text { Epilepsy Center, Osaka } \\
\text { University Hospital; } \\
\text { Department of } \\
\text { Neurosurgery, Osaka } \\
\text { University Graduate } \\
\text { School of Medicine }\end{array}$ & Author & $\begin{array}{l}\text { Decided the } \\
\text { treatment option } \\
\text { for the patient, } \\
\text { revised the } \\
\text { manuscript } \\
\text { for intellectual } \\
\text { content }\end{array}$ \\
\hline $\begin{array}{l}\text { Kuriko } \\
\text { Kagitani- } \\
\text { Shimono, } \\
\text { MD, PhD }\end{array}$ & $\begin{array}{l}\text { Epilepsy Center, Osaka } \\
\text { University Hospital; } \\
\text { Division of } \\
\text { Developmental } \\
\text { Neuroscience, United } \\
\text { Graduate School of } \\
\text { Child Development, } \\
\text { Osaka University; } \\
\text { Department of } \\
\text { Pediatrics, Osaka } \\
\text { University Graduate } \\
\text { School of Medicine, } \\
\text { Suita, Japan }\end{array}$ & Author & $\begin{array}{l}\text { Decided the } \\
\text { treatment option } \\
\text { for the patient, } \\
\text { revised the } \\
\text { manuscript } \\
\text { for intellectual } \\
\text { content }\end{array}$ \\
\hline $\begin{array}{l}\text { Haruhiko } \\
\text { Kishima, } \\
\text { MD, PhD }\end{array}$ & $\begin{array}{l}\text { Epilepsy Center, Osaka } \\
\text { University Hospital; } \\
\text { Department of } \\
\text { Neurosurgery, Osaka } \\
\text { University Graduate } \\
\text { School of Medicine, } \\
\text { Suita, Japan }\end{array}$ & Author & $\begin{array}{l}\text { Major role in the care } \\
\text { of the patient, } \\
\text { decided the } \\
\text { treatment option } \\
\text { for the patient, } \\
\text { revised the } \\
\text { manuscript } \\
\text { for intellectual } \\
\text { content }\end{array}$ \\
\hline
\end{tabular}

\section{References}

1. Gerstmann J. Some notes on the Gerstmann syndrome. Neurology 1957;7:866-869.

2. Binder DK, Podlogar M, Clusmann H, et al. Surgical treatment of parietal lobe epilepsy. J Neurosurg 2009;110:1170-1178.

3. Rusconi E. Gerstmann syndrome: historic and current perspectives. Handb Clin Neurol 2018;151:395-411.

4. Hojo K, Fukushima Y. A case of partial status epilepticus with various neuropsychological symptoms. Folia Psychiatr Neurol Jpn 1979;33:291-294.

5. Shimotake A, Fujita Y, Ikeda A, Tomimoto H, Takahashi J, Takahashi R. Ictal Gerstmann's syndrome in a patient with symptomatic parietal lobe epilepsy [in Japanese]. Rinsho Shinkeigaku 2008;48:208-210.

6. Zollner JP, Haag A, Hermsen A, et al. Ictal conduction aphasia and ictal angular gyrus syndrome as rare manifestations of epilepsy: the importance of ictal testing during video-EEG monitoring. Epilepsy Behav Case Rep 2017;8:55-62.

7. Manford M. Assessment and investigation of possible epileptic seizures. J Neurol Neurosurg Psychiatry 2001;70:3ii-8.

8. Gerstmann J. Syndrome of finger agnosia, disorientation for right and left, agraphia and acalculia: local diagnostic value. Arch Neurol Psychiatry 1940;44:398-408.

9. Tufenkjian K, Luders HO. Seizure semiology: its value and limitations in localizing the epileptogenic zone. J Clin Neurol 2012;8:243-250.

10. Bonini F, McGonigal A, Trebuchon A, et al. Frontal lobe seizures: from clinical semiology to localization. Epilepsia 2014;55:264-277.
Mystery Case responses: A 71-year-old woman with an unusual case of apraxia

The Mystery Case series was initiated by the Neurology ${ }^{\circledR}$ Resident \& Fellow Section to develop the clinical reasoning skills of trainees. Residency programs, medical student preceptors, and individuals were invited to use this Mystery Case as an educational tool. Responses to multiple choice questions formulated using this case were solicited through a group email sent to the American Academy of Neurology Consortium of Neurology Residents and Fellows and through social media. We received 313 responses, $73 \%$ from outside the United States. The majority of respondents $(67 \%)$ had been in practice for 1-4 years; $52 \%$ were residents or fellows while $36 \%$ were faculty/board-certified physicians; the remainder were medical students or advanced practice providers. A wide range of practice settings were represented.

The 71-year-old patient presented with a 6-year history of discrete episodes of acute-onset right hand apraxia, namely finger agnosia, right-left disorientation, dysgraphia, and dyscalculia. Eighty-nine percent of respondents correctly identified this as Gerstmann syndrome. On reviewing the ictal EEG, $80 \%$ of respondents correctly identified lateralized rhythmic delta/theta activity over the left fronto-temporocentro-parietal region, the likely symptomatogenic zone in this case. An FDG-PET scan demonstrated hypometabolism in the left supramarginal and angular gyri, which was correctly identified by $71 \%$ of respondents.

The final question was a test of functional neuroanatomy and $49 \%$ of respondents identified the only incorrectly matched ictal symptom and symptomatogenic zone pair; Gerstmann syndrome is caused by dysfunction to the dominant, not nondominant parietal lobe. The most frequent incorrect answer $(16 \%)$ was hand dystonias and automatisms, which can be localized to the temporal lobe ipsilateral to the automatisms and contralateral to the hand dystonia. ${ }^{1,2}$

This case emphasizes the importance of a careful clinical history and examination of patients presenting with seizures in order to localize the symptomatogenic zone in the absence of structural abnormalities. This is a key contribution of a neurologist to the epilepsy multidisciplinary team in presurgical evaluation. The case also serves as an important reminder that seizures can manifest with negative symptoms, which can be as localizing as the more common positive symptoms, such as hand dystonias or ictal pouting.

Robert Hurford, MSc, MRCP (UK)

Nuffield Department of Clinical Neurosciences, University of Oxford

\section{References}

1. Rusu V, Chassoux F, Landre E, et al. Dystonic posturing in seizures of mesial temporal origin: electroclinical and metabolic patterns. Neurology 2005;65: 1612-1619.

2. Janszky J, Fogarasi A, Magalova V, et al. Unilateral hand automatism in temporal lobe epilepsy. Seizure 2006;15:393-396. 


\section{Neurology}

\section{Mystery Case: Parietal lobe epilepsy with ictal manifestation of Gerstmann syndrome}

Hui Ming Khoo, Yuya Fujita, Naoki Tani, et al.

Neurology 2020;94;e430-e433 Published Online before print January 13, 2020

DOI 10.1212/WNL.0000000000008841

\section{This information is current as of January 13, 2020}

\section{Updated Information \& Services}

References

Subspecialty Collections

Permissions \& Licensing

Reprints including high resolution figures, can be found at: http://n.neurology.org/content/94/4/e430.full

This article cites 12 articles, 2 of which you can access for free at: http://n.neurology.org/content/94/4/e430.full\#ref-list-1

This article, along with others on similar topics, appears in the following collection(s):

Apraxia

http://n.neurology.org/cgi/collection/apraxia

Clinical neurology examination

http://n.neurology.org/cgi/collection/clinical_neurology_examination Partial seizures

http://n.neurology.org/cgi/collection/partial_seizures

Status epilepticus

http://n.neurology.org/cgi/collection/status_epilepticus

Information about reproducing this article in parts (figures,tables) or in its entirety can be found online at:

http://www.neurology.org/about/about_the_journal\#permissions

Information about ordering reprints can be found online:

http://n.neurology.org/subscribers/advertise

Neurology ${ }^{\circledR}$ is the official journal of the American Academy of Neurology. Published continuously since 1951, it is now a weekly with 48 issues per year. Copyright @ 2020 American Academy of Neurology. All rights reserved. Print ISSN: 0028-3878. Online ISSN: 1526-632X.

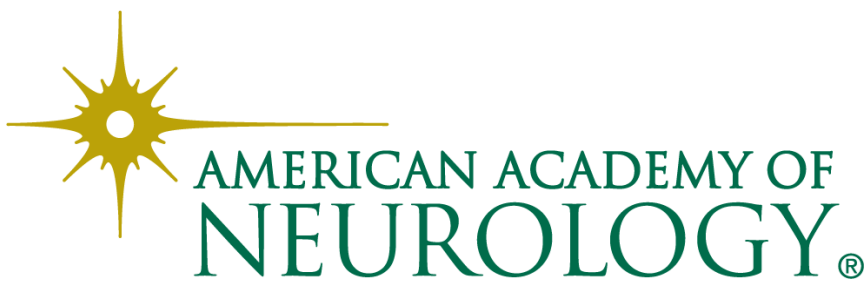

